\title{
Naturales y extranjeros: sobre la construcción de categorías en el mundo hispánico
}

\author{
Tamar Herzog \\ Professor of History \\ Stanford University \\ 450 Serra Mall, Building 200 \\ Stanford, CA 94305-2024, Estados Unidos \\ therzog@stanford.edu
}

Fecha de recepción: 01/04/2011

Fecha de aceptación: 15/12/2011

\section{RESUMEN}

Este ensayo indaga sobre el sentido, utilización y extensión de los conceptos "natural" y "extranjero" tanto en España como en Hispanoamérica durante el período moderno. Aboga por una lectura que destaca i. que la distinción entre naturales y extranjeros no siempre era importante, ni siquiera relevante; ii. que para que haya discusiones al respecto hacía falta una parte afectada y unos intereses concretos; iii. que la naturaleza y la extranjería no eran situaciones concretas sino que reflejaban la existencia de un continuum que iba de los totalmente extranjeros a los totalmente naturales, pasando por una amplia gama de situaciones intermedias; iv. que el discurso sobre la extranjería también se aplicaba a lo que hoy llamaríamos minorías con el fin de discriminarlas.

Palabras clave: natural, extranjero, vecino, gitano, africano, converso, morisco.

\section{Natives and Foreigners: The Construction of Categories in the Early Modern Spanish World}

\begin{abstract}
This essay examines the meaning, uses and extension of the concepts 'native' and 'foreigner' in both Spain and Spanish America during the Early Modern period. It argues: i. that the distinction between natives and foreigners was not always important, not even relevant; ii. that discussions regarding these categories only happened when actors identified particular interests that they were willing to defend; iii. that nativeness and foreignness were not concrete situations but instead reflected the existence of a continuum that connected those totally native and those totally foreign, through a wide range of intermediary situations; iv. that the discourse regarding foreignness was also applied to those we currently identify as minorities in order to discriminate against them.
\end{abstract}

Key words: natives, foreigners, citizens, Gypsies, Africans, Conversos, Moriscos. 
A finales del siglo XVII, el jesuita Samuel Fritz anotó en su diario que los indios de la Amazonía "no han visto más gobernador ni español que a mí"1. Unas décadas después, en 1730, el padre Juan Bautista Julián explicó que trabajaba en el interior americano como "misionero de Castilla" 2 . Ninguna de estas dos afirmaciones hubiera sido sorprendente si no fuera porque tanto Fritz como Julián fácilmente podrían titularse como "extranjeros", siendo el primero nativo de Bohemia y el segundo alemán. Aunque ni uno ni otro explicaban cómo y por qué habían llegado a identificarse como castellano o español, en ambos casos queda patente que ni uno ni otro encontró oposición a la hora de hacerlo. Otras personas, sin embargo, no tuvieron la misma suerte. A mediados del siglo XVIII, Bartolomé Guillén, nacido en Villa San Clemente (Cuenca), fue clasificado como extranjero y, en esta calidad, forzado a exiliarse del Perú ${ }^{3}$. Pocos años después, le pasó lo mismo a Ventura Mariño Barrieros y Figueroa, natural de la villa de Cangas, del Reino de Galicia, "sujeta al Rey Católico de las Españas y nacido de padres notoriamente calificados e ilustres por serlo del capitán de granaderos don Pedro Ventura Mariño y de doña María Barrieros y Figueroa, naturales de dicha villa"4.

Una pregunta se impone: ¿por qué Fritz y Julián -de orígenes claramente extranjero- podían vindicar su condición de españoles y no Guillén y Mariño -nacidos en España de padres naturales (o naturalizados)? ¿Qué era lo que se entendía al reclamar una condición u otra? ¿Qué era lo que se pretendía?

Como he alegado en otros lugares más detenidamente, a partir del siglo XVII (si no anteriormente), la designación de unos y otros como "españoles" era, normalmente, una forma abreviada de referir a su condición de "naturales de los reinos de España," es decir, a su pertenencia a uno de los (muchos) cuerpos de los que España se componía por aquel entonces ${ }^{5}$. Entre los naturales de España se enumeraron los naturales de Castilla, Aragón, Valencia, País Vasco y así sucesivamente. Dependiendo del contexto, se refería a ellos a veces como naturales de un reino particular; otras como "españoles". Lo que tenían todos los "españoles" en común era que, al contrario de los llamados "extranjeros", ellos se consideraban parte de la comunidad política hispana y, en esta virtud, tenían ciertos derechos y obligaciones. Aunque el contenido de éstos variaba dependiendo del lugar y la época, y de si la cuestión que se barajaba era legal o social, política o eclesiástica, doméstica o en la esfera pública, la vindicación de la calidad de "español" se hallaba siempre relacionada con la pretensión de gozar

1 Rodríguez Castelo, Hernán (ed.): Diario del padre Fritz, Quito, Studio 21, 1997 [1697-1703], p. 110.

2 Carta de Juan Bautista Julián al gobernador de Pará, La Laguna, 5 de octubre de 1730, inserta en la carta de éste al rey de Portugal, Belém, 18 de septiembre de 1739: Arquivo Histórico Ultramarino, Lisboa (en adelante AHU), acl_cu_013, cx.22, d. 2082.

${ }^{3}$ Archivo General de la Nación, Lima (en adelante AGNL), Secretaría General, varios 4, cuaderno 122.

4 AGNL, Secretaría General, varios 3, cuaderno 107.

5 Aunque hasta comienzos del XVIII siguieron existiendo naturales de Castilla, naturales de Aragón, naturales de Valencia y así sucesivamente-esta naturaleza distinta fue legalmente, aunque no necesariamente social y políticamente abolida por los decretos de la Nueva Planta de principios de ese siglo-, ya hacia finales del XVI apareció tanto en la documentación judicial como administrativa y privada una naturaleza claramente ligada a cualquier reino peninsular, la que los contemporáneos intercambiaban con el apodo "español". Estos temas y otros se estudian en HeRzoG, Tamar: Vecinos y extranjeros. Hacerse español en la edad moderna, Madrid, Alianza Editorial, 2006 (originalmente publicado bajo el título Defining Nations: Immigrants and Citizens in Early Modern Spain and Spanish America, New Haven, Yale University Press, 2003). 
de un régimen especial, normalmente privilegiado, aunque a veces desaventajado, pero siempre exclusivo. Dado que la condición de natural permitía el acceso a un sistema normativo particular, discusiones en torno a quién era español y quién extranjero aparecían normalmente sólo cuando era necesario distinguir entre unos y otros con el fin de aplicarles este régimen. Tales discusiones tuvieron lugar, por ejemplo, cuando - a raíz del monopolio en las Indias- era preciso clasificar a los candidatos a la inmigración o al comercio con el Nuevo Mundo -sólo los españoles fueron admitidos en él. $\mathrm{O}$, cuando para obtener oficios públicos o beneficios eclesiásticos, hacía falta hacer lo mismo.

Mientras que en estos casos -y muchos otros en los que las reglas sociales, económicas, o jurídicas discriminaban entre naturales y extranjeros- el debate sobre quién era quién podía ser largo e incluso violento, en otras ocasiones, cuando nada parecía estar en tela de juicio, o cuando la agregación de individuos o familias al grupo -tuvieran las características que tuvieran- se consideraba ventajoso, cómo se titulasen y qué condición ostentaban no parecía interesarle a nadie. Parte de cómo funciona el derecho en general -dicho simplemente, las normas sólo se invocan cuando hay razón para hacerlo y cuando hay una parte interesada en ello ${ }^{6}$ en el caso concreto bajo examen también operaba el hecho de que la discriminación entre naturales y extranjeros sólo se aplicaba en ciertos terrenos y no en otros. Cuando ésta no existía, el ser natural o extranjero simplemente no importaba. Nadie se preguntaba a sí mismo qué condición tenía y nadie se interesaba por la condición de los demás, a menos que hubiera una razón para vindicarlas. El ser natural o extranjero, en fin, no era una situación abstracta, sino una observación concreta que se hacía cuando era necesaria. Precisamente por esta razón, en la mayoría de los casos, lugares, personas y circunstancias, nadie sabía qué condición pretendían sus prójimos; y a nadie le importaba, hasta que la misma tuvo implicaciones concretas. Sin éstas, y en ausencia de listas formales de naturales y extranjeros (listas que sólo aparecían en España y no en las Américas, y que eran un invento -sólo parcialmente exitoso- de la segunda mitad del siglo XVIII), la condición de las personas no se discutía, no solo porque no había intereses que defender, sino también porque la misma no tenía relevancia alguna.

Dado que uno vindicaba su condición de natural o extranjero sólo cuando unos intereses concretos lo justificaban, el ser de una calidad u otra sólo se cristalizaba en momentos de crisis (en los que se pretendía cambiar el status quo) o competición (en los que hubo oposición). En las demás circunstancias, nadie inquiría sobre quiénes eran sus prójimos ni a nadie le importaba qué y quién pretendían ser. Esta dinámica explicaría porque Fritz y Julián podían pretender ser españoles sin que nadie les contestara. Su identificación como tales no invocaba privilegios. Al contrario, confesaba su aceptación de serias obligaciones tales como construir misiones, convertir indígenas y conquistar a la vez que defender un territorio dicho español. Mientras tanto, Guillén y Mariño encontraron oposición porque los dos eran comerciantes cuyas actividades mercantiles en las Américas produjeron la contestación de rivales que

\footnotetext{
6 Estas preguntas se estudian más detenidamente en Herzog, Tamar: «Nombres y apellidos: ¿cómo se llamaban las personas en Castilla e Hispanoamérica durante la época moderna?», Jahrbuch für Geschichte von Staat, Wirtschaft und Gesellschaft Lateinamerikas, 44 (2007), pp. 1-36.
} 
quisieron verles salir. Pero, ¿cómo llegaron unos y otros a vindicar esta condición y qué es lo que significaba para ellos?

Volviendo a Fritz y Julián, de sus escritos queda patente que los dos, de origen extranjero, eran miembros de la provincia jesuita de Quito y habían trabajado como misioneros en nombre de la misma y de la corona de España en un territorio cuya jurisdicción se disputaban España y Portugal. Fritz, el más notorio de los dos, era superior de las misiones del Marañón. Durante sus más de treinta años en el interior americano (de 1688 hasta finales de la década de 1710 aproximadamente) no sólo extendió el territorio de las misiones (y por tanto de España), sino que se involucró, abiertamente, en el conflicto jurisdiccional entre las dos potencias. Fritz envió informes a Quito, Lima y Madrid, así como a los embajadores en Lisboa y Roma, explicando que lo suyo era salvar almas, no conquistar tierras. Fritz, sin embargo, defendió los derechos de España con la convicción de que sólo éstos garantizarían la permanencia y éxito de su misión ${ }^{7}$. Usando su vasto conocimiento de la región y de su población autóctona y a base de sus frecuentes encuentros con frailes y soldados portugueses que le requerían constantemente a abandonar un territorio que ellos consideraban suyo, Fritz se convirtió a principios del siglo XVIII en un testigo tan ocular como experto. No sólo discutía con portugueses su versión de los hechos, sino que resistía a sus presiones -a menudo voceadas por tropa de guerra- para que abandonase el territorio. Apreciado por las autoridades hispanoamericanas y peninsulares, los portugueses le consideraron un espía y le acusaron de defender los intereses de España y, en general, de portarse como español en vez de jesuita ${ }^{8}$. Era precisamente contra los portugueses que, en estas conversaciones, Fritz se identificaba como "jesuita misionero de España", y ellos le tomaron por tal. Su identificación como español era tan acusada que los portugueses incluso llegaron (o intentaron llegar -esto no queda claro-) con él a acuerdos -siempre provisionales- sobre la jurisdicción de una u otra corona ${ }^{9}$. No es de sorprender tampoco que los indígenas -según su versión- también le considerasen como español. Después de todo, ellos eran también testigos oculares de su defensa de los intereses de España; ellos también entendieron que la conversión religiosa conllevaba la conversión cívica, por lo que tras su cristianización quedaron sujetos a España; Fritz, responsable de esta mutación de doble vertiente, podía considerarse español también porque no era portugués (sólo españoles y portugueses se hallaban en estos terrenos) y porque

\footnotetext{
7 Archivo General de Indias (en adelante AGI), Quito, 158, ff. 14v-17v: Informe del padre Samuel Fritz, 23 de marzo de 1721. Ver también RodríGuez Castelo: op. cit. (nota 1), p. 95.

8 AHU, acl_cu_013,cx.4,d.340: Consulta del conselho ultramarino para el rey, Lisboa, 12 de noviembre de 1697. En 1689 y 1705, Fritz fue nuevamente identificado como un "padre castellano": RodRíGUEz CASTELo: op.cit. (nota 1), p. 86 y "Relação da jornada do Solimões e Rio Negro por Frei Vitoriano Pimentel” fechada el 7 de septiembre de 1705 y reproducida en CARVALHo, João Renôr F. De: «Presencia e permanência da ordem do Carmo no Solimões e no Rio Negro no século XVIII», en Das reduções latino-americanas às lutas indigenas actuais: IX simpósio latinoamericano do CEHILA, San Pablo, Ed. Paulinas, 1982, pp. 175-190.

9 Requerimineto del padre Fritz al cabo de escolta Joseph Antunes da Fonsequa (20 de abril de 1697) y la respuesta de éste (22 de abril de 1697) en "Consulta do conselho ultramarino para o rei sobre o missionário jesuita castelhano padre Samuel”, Lisboa, 12 de noviembre de 1697: AHU, acl_cu_013, cx.4, d.340 y RodríGUEZ CASTELO: op. cit. (nota 1), p. 132.
} 
en muchas ocasiones él mismo explicaba a los nativos la diferencia entre unos y otros. Según su propio testimonio, lo hacía al admitir en su misión a indígenas procedentes de territorios lusitanos, prometiéndoles mejor trato porque ahora estaban bajo la protección de España ${ }^{10}$.

Aunque Julián nunca llegó a tales extremos, es evidente que su labor en la Amazonía era bastante similar. Respondiendo a reclamos portugueses, en la década de 1730, Julián, que lideraba las misiones de la zona, afirmaba los derechos de España una vez tras otra, tanto de forma tangible - construyendo y defendiendo misiones- como por escrito -alegando a favor de los mismos y refutando los argumentos jurídicos de sus rivales ${ }^{11}$. No sólo escribió a las autoridades españolas, sino que mantuvo una prolija correspondencia con gobernadores portugueses, con quienes intercambiaba opiniones y a cuyos enviados especiales recibía en sus misiones con el fin de oírles, refutar sus alegatos, barajar soluciones y proponer treguas. Como Fritz, en virtud de estas actividades, Julián acabó identificándose de tal grado con Castilla que todos, portugueses e indígenas incluídos, le consideraban como español ${ }^{12}$.

Mientras tanto en Lima, a Bartolomé Guillén y a Ventura Mariño Barrieros y Figueroa se les denegaba su condición de naturales. ¿Por qué? Aunque escueta, la documentación de la que disponemos es sin embargo esclarecedora. Según los testigos reunidos primero por el tribunal del consulado y luego por un oidor de la audiencia, en el caso de Bartolomé Guillén "no se necesita para saber que es francés más ejecutoria que la firma que pone en el escrito de dicha hoja... porque es letra tan extranjera, como es su habla, de modo que en habla y letra tiene dos irrefragables testigos de su extranjería" ${ }^{13}$. Mientras a Guillén se le encontraron indicios de una educación foránea, Mariño, al contrario, fue clasificado como extranjero en base a su apellido que, según las declaraciones, era típicamente portugués ${ }^{14}$. En ambos casos se trataba de rasgos exteriores que algunas personas poco conocedoras de su historia individual, su origen o ascendencia, interpretaron de modo perjudicial. Y, sin embargo, examinadas de cerca, las sospechas se disipaban. Resultó que Guillén era hijo de un padre naturalizado pero que, por ley, tanto su padre como él ya eran naturales y por tanto españoles. Mariño, al contrario, era gallego. En Galicia, se admitía entonces, hubo giros que parecían portugueses y sin embargo no lo eran. En estas ocasiones -como en muchas otras- los que debatían la extranjería de sus prójimos no tuvieron más remedio que admitir que presunciones culturales y linguísticas - que relacionaron el ser español con una manera de hablar, escribir y ser- no siempre indicaban la solución

\footnotetext{
10 Rodríguez Castelo: op. cit. (nota 1), pp. 131 y 133.

11 Carta de Juan Bautista Julián al gobernador de Pará, Laguna, 8 de septiembre de 1732: AGI, Quito, 158, ff. $14 \mathrm{r}-15 \mathrm{v}$.

12 Carta de Juan Bautista Julián al gobernador de Pará, Laguna, 5 de octubre de 1730, anejo a la carta del gobernador y capitán general del estado de Maranhão y Pará, João de Abreu de Castelo Branco, para el rey. Belém, 18 de septiembre de 1739: AHU, acl_cu_013, cx.22, d. 2082 y "Certidão dos capítulos do regimento referente aos limites de ocupação dos territórios pelos missionários portugueses e espanhóis”, Belém, 18 de octubre de 1731: AHU, acl_cu_013, xc.13, d. 1207. Vid, igualmente, el reclamo del sargento mayor Melchior Mendes, Laguna, 6 de septiembre de 1732: AGI, Quito, 158, ff. 13r-v y requerimiento hecho por Juan Bautista Julián a Melchior Mendes: AGI, Quito 158, ff. 16r-v.

13 AGNL, Secretaría General, varios 4, cuaderno 122.

14 AGNL, Secretaría General, varios 3, cuaderno 107, ff. 12v-13r.
} 
correcta ${ }^{15}$. Por un lado, los extranjeros naturalizados no siempre cambiaban su modo de ser -y al contrario de hoy en día nadie les exigía tal mutación, ni siquiera que hablesen castellano u otro idioma peninsular correctamente. Por otro, España consistía de un espacio multilinguístico, donde los naturales podían hablar castellano, pero también catalán, valenciano, gallego, euskera y así sucesivamente. Que los indicadores externos podían producir conclusiones erróneas era también evidente por el hecho de que muchos extranjeros pretendían ser naturales sin que nadie, jamás, sospechara de que no lo eran ${ }^{16}$. José Manuel Rebelo, por ejemplo, pudo conseguir nombramiento como alcalde ordinario en Buenos Aires precisamente porque nadie imaginaba que era extranjero ${ }^{17}$. El suyo no era el primer caso: los libros del cabildo de la ciudad evidenciaban, más bien, que ésta era la práctica habitual. No era de sorprender, por tanto, que a finales del siglo XVII las autoridades del Perú se quejaran de que, en ausencia de una confesión del interesado, aclarando su condición, era prácticamente imposible saber quién era quién y quién merecía qué trato ${ }^{18}$.

Por un lado, la naturaleza y la extranjería sólo importaban cuando existían conflictos o podía haberlos; por otro, presunciones que asumían que quien obraba como español y protegía a los intereses de España era español o las que, al contrario, pretendían que quien hablaba mal castellano era extranjero, o las que, en general, creían que tanto una condición como otra eran "evidentes", no siempre eran útiles, ni producían conclusiones correctas. Pero la dificultad de saber quién era quién no sólo consistía en averiguar si la pregunta era importante (es decir, a quién le importaba la respuesta, por qué y cuándo) y cuáles eran las pruebas. Requería, además, descifrar exactamente qué implicaba la condición de natural o extranjero y a qué situaciones remitía. Mientras hoy en día tendemos a pensar que estas categorías son excluyentes y opuestas ("o uno es español, o uno es extranjero"), es evidente que durante la época moderna se trataba más bien de un continuum que permitía la existencia de personas totalmente naturales y totalmente extranjeras (como pasa actualmente) pero que admitía también una tercera categoría que incluía a una amplia gama de situaciones intermedias. Es decir, mientras que entre los claramente naturales se hallaban los nacidos en el territorio de padres y abuelos naturales, quienes hablaban castellano correctamente, cuyo nombre era castellano, quienes residían en el territorio y se comportaban como españoles, ante todo, mediante manifestaciones de lealtad a la comunidad a la que pertenecían y, entre los claramente extranjeros, estaban los que no ostentaban ninguna de estas condiciones, en la gama intermediaria estaban todos los demás: los que nacidos en la Península ya no vivían en ella, o no hablaban castellano, o sus padres no eran naturales, o los que no habían nacido en las Españas pero hablaban castella-

15 Herzog, Tamar: «Lengua y pertenencia en la América Española, siglos XVI-XVIII», Ínsula, 762 (2010), pp. 7-10.

16 AGNL, Real Tribunal del Consulado, 252/61, f. 1v.

17 Cabildos de 3 de enero y 27 de junio de 1795 y de 12 de enero de 1796, Acuerdos del extinguido cabildo de Buenos Aires, Buenos Aires, Archivo General de la Nación, 1907-1934, vol. 10, pp. 465 y 515 y vol. 11, p. 16, respectivamente.

18 "La averiguación de esta materia [quién era extranjero] es muy dificultosa, pues en las Indias pocos o ningunos solicitan mantenerse en ellas confesando ser franceses, ingleses, holandeses ni de otra nación, sino la de castellanos, andaluces, navarros y vizcaínos, usando la cautela de mudarse el nombre por si llegase el caso de la pesquisa de averiguarles la patria": AGI, Lima, 81, no. 4, doc. 20, carta del virrey interino del Perú al rey, 11 de agosto de 1681. 
no, eran de padres castellanos, y así sucesivamente. En todos estos casos, en tela de juicio no estaban las dificultades probatorias (cómo se probaba la condición de cada cual) sino preguntas de fondo. Porque la naturaleza y la extranjería no eran un estatus fijo, sino más bien una clasificación que reflejaba la situación que unas personas tenían en relación con el grupo social que les rodeaba, este reflejo no sólo cambiaba continuamente sino que era además plurivalente. Construido de varios elementos y factores, la pregunta consistía siempre en saber qué valor dar a cada uno de ellos y cómo calcular la suma total, deduciendo si la persona reunía o no las características mínimas para ser natural o extranjero ${ }^{19}$. Las leyes tal vez indicaban prima facie qué elementos y valores tener en cuenta, pero nunca pretendían enumerarlos o juzgarlos de modo concluyente. Más bien, enviaban a la doctrina jurídica que mandaba valorar cada hecho de por sí y en combinación con otros, construyendo un resultado debatible, aunque muchas veces consensual. Precisamente por ello, era importante tener en cuenta no sólo la presunción legal que quien había nacido en España de padres naturales era natural, sino contrastarla también con otros elementos como, por ejemplo, su comportamiento después de nacer. Cumplir con lo que la mayoría de los historiadores habían considerado como requisitos legales de la naturaleza no bastaba, ni carecer de ellos indicaba necesariamente que uno era extranjero. Una conclusión se impone: aunque hubo naturales y extranjeros, más que condiciones concretas, se trataba de dos extremos de un continuum que iba de los completamente (y claramente) naturales a los completamente (y claramente) extranjeros, pasando por una variedad de situaciones intermedias que indicaban la posibilidad, por ejemplo, de que uno fuera más extranjero que natural, o más natural que extranjero. $\mathrm{O}$, dicho de otro modo, no se trataba sólo de la pregunta de quién era natural y quién extranjero, sino hasta qué grado y en qué manera.

De la documentación modernista es evidente, además, que la extranjería no sólo operaba con respecto a comunidades que hoy en día caracterizamos como estatales o nacionales. La extranjería local, que distinguía entre "vecinos" y "forasteros", por ejemplo, era altamente importante y sus resultados a veces más impactantes que los provocados por la extranjería al reino ${ }^{20}$. Los vecinos podían usar la propiedad comunal, ostentar oficios de la república y formar parte del ayuntamiento. Eran también los que podían recibir terrenos, o arrendar el uso de otros. En algunos pueblos, sólo ellos podían participar en ciertas fiestas o compartir comida y vino con sus prójimos.

Durante el período moderno, además, la extranjería servía también como un discurso genérico, empleado contra cualquier grupo considerado externo, permitiendo excluir a sus miembros de ciertos beneficios. De esta manera, por ejemplo, en algunas ocasiones y tiempos, entre extranjeros también se enumeraban a los "españoles de origen africano" (según se llamarían luego en la Constitución de Cádiz), los gitanos y los conversos y moriscos. A todos ellos se les achacaba, precisamente, el no ser totalmente leales a la comunidad española, o no estar totalmente integrados en ella y, por esta razón, ser extranjeros. Los españoles de origen africano, se decía, estaban sujetos a monarcas foráneos y su emigración a los dominios españoles no era volun-

19 Herzog: op. cit. (nota 5), pp. 107-175.

20 Herzog: op. cit. (nota 5), pp. 47-106. 
taria ya que habían sido traídos como esclavos con suma violencia. En consecuencia, la misma no podía dar indicación -como hacía en caso de inmigrantes "normales"-ni de su lealtad ni de su integración en el reino ${ }^{21}$. Los gitanos, se argumentaba, se debían rechazar porque eran diferentes. A veces se afirmaba que eran extranjeros; en otras ocasiones se insistía en que no formaban parte de una nación distinta sino que eran, simplemente, españoles de mal vivir ${ }^{22}$. Sin embargo, incluso cuando se les achacaba de ser españoles, aunque desobedientes, la legislación que les discriminaba insistía en su extranjería. Les prohibía usar su lengua propia, su vestido particular y, en general, todos los rasgos que les distinguían de los demás ${ }^{23}$. La misma también revelaba que por más que se comportasen bien, quien una vez era gitano siempre lo sería ${ }^{24}$. Los gitanos eran conscientes de esta realidad. Para poder esquivar las consecuencias de las medidas anti-gitanas, lo único que podían hacer era pedir su naturalización ${ }^{25}$. De manera algo similar, los conversos y moriscos (y sus descendientes) tal vez nacieron en la Península de padres locales, pero (según sus rivales) su fe religiosa les apartaba de los demás, con quienes no se casaban, apenas tenían relaciones sociales y de quienes, en general, mantenían la distancia ${ }^{26}$. Mientras ellos insistían en que España era su patria y ellos eran buenos ciudadanos, sus vecinos que les discriminaban alegaban que no lo eran. De cepa extranjera y de modales distintos, ni formaban parte de la

21 El cabildo de Caracas, 28 de noviembre de 1796. Reproducido en Blanco, José Félix (ed.): Documentos para la historia de la vida pública del Libertador, Caracas, «La Opinión Nacional» (1875), vol. 1, pp. 267-275; PARRY, J.H.: The Age of Reconnaissance. Discovery, Exploration and Settlement 1450-1650, Berkeley, University of California Press, 1981 [1963], p. 317 y BERnAND, Carmen: «Negros, esclavos y libres en las ciudades hispanoamericanas», en Gallego, José Andrés (ed.): Nuevas Aportaciones a la historia jurídica de Iberoamérica [CD-ROM], Madrid, Fundación Tavera, 2000, pp. 9-10 y 50-51.

22 Solicitud de las Cortes de Castilla de 1619, reproducida en la Cédula de 11 de noviembre de 1692 en Archivo de la Chancillería de Valladolid (en adelante ACV), Secretaría del Acuerdo, Cédulas y Pragmáticas, C.8-66, capítulo 1 de la pragmática de 19 de septiembre de 1783, citado en la pragmática de 28 de febrero de 1784 en Archivo General de Simancas (en adelante AGS), Gracia y Justicia, 1004 y Gómez Alfaro, Antonio: La gran redada de gitanos. España: La provisión general de gitanos de 1749, Madrid, Presencia Gitana, 1993, p. 13.

23 Esta legislación, continuamente repetida durante los siglos XVI, XVII e incrementada en el XVIII, se recoge, por ejemplo, en ACV, Secretaría del Acuerdo, Cédulas y Pragmáticas, C.8-66, C.8- 88, C.10-88, C.10-139, C.12-8m C.12-18 y C.12-53 y AGS, Gracia y Justicia, 1004. Muchas de estas normas fueron reproducidas parcialmente en la Novísima Recopilación, Título 16, Libro 12. La persecución de gitanos ha generado una amplia bibliografía. Vid, por ejemplo, SÁnchez Ortega, María Elena: Documentación sobre la situación de los gitanos españoles en el siglo XVIII, Madrid, Editora Nacional, 1976 y Los gitanos españoles. El período Borbónico, Madrid, Castellote, 1977; LEBLON, Bernard: Les Gitans d'Espagne. Le prix de la différence, París, Presses Universitaires de France, 1985 y PEÑAFIEL, Ramón Antonio: «Gitanos en Murcia en la primera mitad del siglo XVIII: ¿Integración o extinción?», Anales de Historia Contemporánea, 4 (1985), pp. 7-34.

24 Solicitud de 16 de diciembre de 1745, citada en la Pragmática de 19 de julio de 1746, en ACV, Secretaría del Acuerdo, Cédulas y Pragmáticas, C.12-18.

25 Solicitud de Baltazar Vargas, mayo de 1797, Archivo de la Villa de Madrid, Secretaría 2-348-62 y SÁNCHEZ ORTEGA: op. cit. (nota 23, 1977), pp. 159-160 y 163-165 y op.cit. (nota 23, 1976), pp. 248-250. Lo mismo opinaron los observadores extranjeros, quienes argumentaron que, aunque los gitanos podían considerarse naturales, en general se les consideraba extranjeros: VAux De Foletier, François: «La rafle des gitans d'Andalousie en 1749 d'après des documents français», Etudes Tsiganes, 23, nos. 1-2 (1977), pp. 5-9, en pp. 6-7.

26 El caso más destacado y debatido era el estatus de los chuetas, los mallorquines de dicho origen converso. Su caso ha sido estudiado por muchos. Vid, por ejemplo, PAZ, Julián: «Reclamaciones de los mallorquines llamados de la calle sobre su condición social», Revista de archivos, bibliotecas y museos, 16 (1907), pp. 184-200; CORTÉs CoRTÉs, Gabriel: Historia de los judios mallorquines y de sus descendientes cristianos, Palma de Mallorca, M. Font, 1985; IsaAc, Lionel A: Els jueus de Majorca, Palma de Mallorca, M. Font, 1986; Poqueres i Gené, Enric: Lourde Alliance. Mariage de Juifs Convertis à Majorque (1435-1750), París, Kimé, 1995; y Herzog, Tamar: op.cit. (nota 5), pp. 183-189. 
sociedad, ni podían admitirse en su seno ${ }^{27}$. No se trataba de cuestiones teóricas. La clasificación de los miembros de estos grupos -nacidos en África, gitanos, conversos y moriscos- como extranjeros (o "semi-extranjeros," o "más extranjeros que naturales") no sólo les estigmatizaba socialmente sino que, además, limitaba su radio de acción al adjudicarles, en vez de los derechos de los naturales, el trato reservado a extranjeros ${ }^{28}$.

Algo similar pasó en las Américas donde, por un lado, los indígenas eran y se consideraban como "naturales" y, por otro, hubo quien dudaba de si esta naturaleza les convertía en españoles o les mantenía como extranjeros ${ }^{29}$. Aunque la discusión siguió durante todo el período colonial, la respuesta dependía no sólo del binomio español-indígena, sino también de qué español y qué indígena se trataba, cuándo y por qué. Siguiendo esta lógica, naturales que ostentaban la condición de caciques se equiparaban con nobles y, en esta calidad, con españoles. El razonamiento que empleaban era simple: en las Américas los españoles no pagaban impuestos. Por no ser pecheros eran todos, por definición, nobles. Y, si todos los españoles eran nobles, la conclusión de que todos los nobles, por implicación, eran españoles se imponía. Nobles de origen indígena, por tanto, no eran "nativos" sino "españoles" 30 . Argumentos similares fueron empleados por las élites de Tlaxcala quienes, en virtud de su alianza con los españoles y su colonización del norte mexicano, se consideraban conquistadores (y no conquistados), colonizadores (y no colonizados) y españoles (y no naturales $)^{31}$. Si, por un lado, estos reclamos indicaban que en el Nuevo Mundo el significado de ser "español" pudo haberse variado por no indicar ya al no-extranjero, sino al no-indígena, por otro era evidente que la discusión sobre quién era español y quién indígena seguía reflejando la división entre naturales y extranjeros, ya que de la respuesta dependía, por ejemplo, si los indígenas podían ocupar cargos públicos y beneficios eclesiásticos ${ }^{32}$.

27 Este diálogo, tal vez monólogo, fue reproducido, por ejemplo, en la solicitud de los chuetas de 12 de febrero de 1773 y la respuesta de la Audiencia de Mallorca de 4 de mayo de 1774, ambas en AGS, Gracia y Justicia, 1021, publicadas también parcialmente por PÉREz MARTínez, Lorenzo (ed.): Revindicación de los judios mallorquines (Documentos para su estudio I), Palma de Mallorca, Fontes Rerum Balearius, 1983.

28 Herzog: op. cit. (nota 5), pp. 177-204.

29 En 1598, por ejemplo, Baltasar Álamos de Barrientos indicó que en el Nuevo Mundo existían dos clases de naturales: los indios, que eran naturales por origen, y los españoles, que lo eran por nacimiento: Álamo DE BARRIENTOS, Baltasar: Discurso politico al rey Felipe III al comienzo de su reino, Madrid, Anthropos, 1990 [1598], p. 14.

30 Hitl, Ruth: «Teaching the Pre-History of Race Along the Hispanic Transatlantic», Dieciocho, 30 (1) (2007), pp. 105-118, en p. 105.

31 Matthew, Laura y Oudisk, Michel R. (eds.): Indian Conquistadors: Indigenous Allies in the Conquest of Mesoamerica, Norman, University of Oklahoma Press, 2007.

32 Solórzano Pereira, Juan: Política Indiana, Madrid, Compañía Iberoamericana de Publicaciones, 1972 [1648], libro 2, cap. 29, puntos 25-34, cédulas del 19/12/1696, 26/3/1697, 27/11/1703, 21/2/1725 y 11/9/1766, reproducidas en Konetzke, Richard: Colección de documentos para la historia de la formación social de Hispanoamérica 14931810, Madrid, CSIC, 1953, vol. 3 (1), pp. 64-69, 93-94, 186 y 333-334. Vid, igualmente, Muro OreJón, Antonio: Cedulario americano del siglo XVIII, Sevilla, Escuela de Estudios Hispanoamericanos, 1956-1977, vol. 1, pp. 60260 y en su «La igualdad entre indios y españoles: La real cédula de 1697», en Estudios sobre politica indigenista española en América, Valladolid, Universidad de Valladolid, 1975, vol. 1, pp. 365-386. La pregunta fue finalmente respondida formalmente (y coherentemente) sólo en Cádiz: Constitución de Cádiz, título 1, cap.1, art.1: "La nación española es la reunión de todos los españoles de ambos hemisferios" y cap. 2, art. 5, "son españoles primero todos los hombres libres nacidos y avecindados en los dominios de las Españas y los hijos de éstos”. El título 2, cap.1, art. 10 concretiza que el territorio de las Españas incluye las provincias peninsulares así como las posesiones en África, 
Porque la naturaleza tuvo todas estas características, en ocasiones, pudo ser manipulada, permitiendo a los interesados escoger la condición que más les convenía. Esta era, por lo menos, la queja de muchos, quienes apuntaron -por ejemplo a mediados del siglo XVIII- que entre los que pretendían ser extranjeros habían muchos naturales y viceversa. Su adhesión a una u otra condición no era sincera ni permanente. En palabras de la Junta de Comercio y Agricultura de Valencia (1773):

[Ellos] participan (aunque no lo quieren confesar) en los mismos beneficios que los naturales en el interior del reino, y aunque no lograsen otro que venir a él con tan humildes y bajos principios y labrarse su fortuna con perjuicio de vuestros vasallos, que en su defecto harían lo mismo y tomarían esta carrera, parece que eran suficientes para que abrazasen gustosos las leyes fundamentales de este reino y obedeciesen vuestros suaves y soberanos preceptos ciegamente. Al contrario, Señor: los resisten con todas sus fuerzas y no omiten medio por irregular que sea para no observarlos ${ }^{33}$.

Al resentimiento le acompañaba la exigencia de que quienes se beneficiaban de los privilegios de naturales fuesen inducidos a cumplir los deberes correspondientes.

Este tipo de quejas produjeron en la España peninsular proyectos destinados a distinguir entre "verdaderos extranjeros" y "extranjeros fingidos" que eran, en realidad, naturales. La meta no era de saber quién era quién en abstracto, sino asegurar que cada cual tuviese el trato que merecía y que los privilegios correspondiesen con las obligaciones. El intento más conocido entre todos de promover esta claridad era la orden que Madrid envió a las autoridades locales para elaborar listas de extranjeros ${ }^{34}$. Puesta en práctica, la campaña de enumeración se reveló muy complicada. Aunque las instrucciones dadas reproducían los debates (y criterios) anteriores que sostenían, por ejemplo, que todos los avecindados y arraigados, los que nacieron en España, los que recibieron cartas de naturaleza, habían establecido domicilio, habían recibido la vecindad en una comunidad local española, se habían casado con una española, habían adquirido propiedades, habían trabajado como en oficios reservados a naturales, habían actuado como vecinos utilizando la propiedad municipal, habían residido en España durante más de diez años con casa abierta, o, de otro modo según el derecho común o real habían obtenido la naturaleza o la vecindad en España, eran naturales, la elaboración de listas se encontró con serias dificultades. Por un lado, la comunidad extranjera residente en España se negó a colaborar; por otro, al intentar definir la situación de las personas de forma genérica (y no individual, caso por caso), la complejidad del binomio extranjero-natural se hizo patente. Tanto las autoridades locales como regias concluyeron entonces lo evidente: que más que una oposición entre unos y otros lo que había era un continuum; que saber quién era extranjero y quién natural era altamente difícil y que esta condición podía cambiarse enseguida. Los que se llamaban a declarar su condición lo mostraron con creces: muchos, argumentando

\footnotetext{
América y Asia y, finalmente, título 2, cap. 4, art. 18 define como ciudadanos españoles a los que "por ambas líneas traen su origen de los dominios españoles de ambos hemisferios y están avecindados".

33 Su carta, fechada en Valencia, 3 de abril de 1773: Archivo Histórico Nacional (en adelante AHN), Estado, $629-3 / 66$.

34 Herzog: op. cit. (nota 5), pp. 130-140.
} 
que eran naturales cuando les convenía, negaron esta condición cuando esto les venía mejor. Juan Bautista Valerino, alcalde de barrio de Sevilla, declaró, por ejemplo, que no tenía domicilio ninguno en la ciudad. En Orán, Juan Pedro Prats, casado con una española, padre de cinco hijos, y poseedor de una tienda de venta al por menor y una casa, declaró su extranjería. Mientras tanto, otros individuos que acababan de llegar afirmaron que eran naturales. Un tercer grupo se movía entre una posición y otra. Miguel Charles y Pedro Constayns declararon ser vecinos y naturales cuando solicitaron su admisión al gremio local, pero insistieron en que eran extranjeros cuando se les pidió pagar impuestos ${ }^{35}$.

Intentos de ordenar este caos siguieron hasta finales del siglo XVIII y posiblemente después ${ }^{36}$. Su fracaso dio prueba, ante todo, de la volatilidad de unas condiciones (la naturaleza y la extranjería) cuyo peso práctico podía ser enorme, pero cuyo alcance y definición no eran nada claros. Reuniendo una serie de características culturales, sociales, económicas y políticas, la importancia de cada una de éstas en cada caso particular dependía de quién preguntaba y por qué. Y, mientras se barajaban algunos criterios objetivos como, por ejemplo, el lugar de nacimiento y la ascendencia, al final lo que más importaba era el comportamiento de cada cual. Como si se tratara de una verdadera actuación teatral (performance theory), a veces contaba más lo que uno pretendía ser, de lo que era. $\mathrm{O}$, dicho de otro modo, lo que los demás le permitían reclamar con su silencio. A veces, el ser o no natural no importaba. En otros casos, la pregunta de quién era quién se imponía. Hubo quien pretendía adquirir una condición u otra siguiendo criterios estratégicos; otros vivían la naturaleza o la extranjería como una condición impuesta desde fuera. En ocasiones se trataba de una evaluación positiva que reconocía la pertenencia de uno; en otras era más bien una designación negativa que clasificaba a los demás como rivales. Una suerte echada o reclamada por uno mismo, fuera el caso el que fuera, lo que quedaba patente era que durante la época moderna la designación de unos como naturales y de otros como extranjeros nunca era ni inocente ni evidente.

35 Carta del marqués de Croix a la Junta de Comercio, Moneda y Dependencias de Extranjeros, 16 de marzo de 1765: AHN, Estado 647/21, y los debates en AHN, Estado 629-1/4 y 629-3/63.

36 Sobre la vigencia de estas categorías y debates más allá del antiguo régimen vid Herzog, Tamar: «Communities Becoming a Nation: Spain and Spanish America in the Wake of Modernity (and Thereafter)», Citizenship Studies, 11 (2) (2007), pp. 151-172. 